\title{
The employment of FTIR spectroscopy and chemometrics for the classification and prediction of antioxidant activities of pumpkin seed oils from different origins
}

\author{
Irnawati Irnawati1 ${ }^{1,2}$, Sugeng Riyanto ${ }^{1}$, Sudibyo Martono ${ }^{1}$, Abdul Rohman ${ }^{1,3^{*}}$ \\ ${ }^{1}$ Department of Pharmaceutical Chemistry, Faculty of Pharmacy, Universitas Gadjah Mada, Yogyakarta 55281, Indonesia. \\ ${ }^{2}$ Faculty of Pharmacy, Halu Oleo University, Kendari 93232, Indonesia. \\ ${ }^{3}$ Center of Excellence Institute for Halal Industry \& Systems, Universitas Gadjah Mada, Yogyakarta 55281, Indonesia.
}

\section{ARTICLE INFO \\ Received on: 02/10/2020 \\ Accepted on: 14/02/2021 \\ Available online: 05/05/2021}

Key words:

Antiradical scavenging

activities, pumpkin seed oil,

chemometrics, FTIR spectra, geographical origin.

\begin{abstract}
Vegetable oils, including pumpkin seed oil (PSO), contained triacylglycerols and some minor components including phenolics and tocopherols which are believed to contribute to antioxidant activities. The objective of this research was (1) to determine the antioxidant activities of PSOs from different origins using 2,2'-diphenyl-1-picrylhydrazil (DPPH) radical scavenging, (2) to classify PSOs from different origins using principal component analysis (PCA) and cluster analysis (CA), and (3) to predict the antiradical activities of PSO based on Fourier transform infrared (FTIR) spectra using multivariate calibration of partial least square regression (PLSR). The antioxidant activities of PSOs were evaluated based on the capability of PSOs to reduce the absorbance values of DPPH. Classification of PSOs from different origins was evaluated using PCA and CA using variables of absorbance values of FTIR spectra, while prediction of antiradical activities using FTIR spectra was facilitated by PLSR. The results showed that radical scavenging activity (RSA) of PSO from Gunung Kidul and Tawangmangu had the highest RSA accounting for $98.71 \%$ $\pm 0.02 \%$ and $83.57 \% \pm 0.13 \%$, respectively. PCA could classify PSO from different origins using the variable of FTIR spectra absorbances based on PC1 and PC2 score plots. CA using the same variables could group PSO samples into five groups based on the dendrogram obtained. PLSR using the first derivative FTIR spectra at $3,500-650 \mathrm{~cm}^{-1} \mathrm{could}$ predict RSA of PSO with $R^{2}$ values of 0.9996 and 0.9418 in calibration and validation models, while the root mean square error of calibration and the root mean square error of prediction were of $0.425 \%$ and $4.93 \%$, respectively. It can be concluded that FTIR spectra combined with chemometrics are effective means for the classification of PSO from different origins and for the prediction of antioxidant activities of PSO with accurate and precise results.
\end{abstract}

\section{INTRODUCTION}

Currently, edible vegetable oils are taken into account as major economic resources in certain nations. Vegetable oils are typically applied in some industries such as food, pharmaceuticals, cosmetics, and oleochemicals. In view of the nutritional aspects,

\footnotetext{
"Corresponding Author Abdul Rohman, Department of Pharmaceutical Chemistry, Faculty of Pharmacy, Universitas Gadjah Mada, Yogyakarta 55281, Indonesia; Center of Excellence Institute for Halal Industry \& Systems, Universitas Gadjah Mada, Yogyakarta 55281, Indonesia.

E-mail:abdul_kimfar@ugm.ac.id
}

vegetable oils also contain some bioactive compounds like essential fatty acids, fat-soluble vitamins, and phenolic compounds needed in human metabolism and energy sources (Zhang et al., 2012). Pumpkin seed oil (PSO), extracted from pumpkin (Cucurbita maxima) seeds, has been known as a functional oil due to its active components with certain biological activities (Rohman and Irnawati, 2020). PSO is reported to contain phenolic compounds, tocopherols, and carotenoids. These compounds are well known as a source of natural antioxidants (Al-Farsi et al., 2005). Several researches have reported the antioxidant activity of PSO using in vitro methods including 2,2'-diphenyl-1-picrylhydrazil (DPPH) radical scavenging assay and $\beta$-carotene/linoleic acid bleaching test and correlated these antioxidant activities with phenolics compounds (Jiao et al., 2014; Kulaitienè et al., 2018; Rezig et al., 
2018; Siano et al., 2016). However, the determination of antioxidant activities using physicochemical tests involved reagents and several analytical steps; as a consequence, some fast techniques like the Fourier transform infrared (FTIR) spectroscopy method are continuously developed for measurement antioxidant activities.

Antioxidants are typically defined as any substance or any compound either synthetic or natural having the capability to significantly delay or prevent the oxidation reactions of the substrate when present at low levels compared with those of an oxidizable substrate (Rohman et al., 2020a). Due to some restrictions regarding the use of synthetic antioxidants, the natural antioxidants coming from plants are explored and developed, and among these are antioxidants from vegetable oils (Widodo et al., 2019). Some evaluations on antioxidant activities in vitro have existed in the scientific literature including 1,1-diphenyl-2-picrylhydrazyl radical scavenging assay, Trolox equivalent antioxidant capacity method known as 2,2'-azino-bis (3-ethylbenzthiazoline-6-sulfonic acid) radical cation decolorization assay, lipid peroxidation inhibition assay, beta-carotene bleaching method, metal chelating assay Ferric thiocyanate method, and cupric ion reducing antioxidant capacity method (Alam et al., 2013). DPPH radical scavenging assay is the most popular method applied for screening the antioxidant activities of edible fats and oils (Marina et al., 2009).

With the development of chemometrics or multivariate data analysis, some chemists tried to correlate the antioxidant with spectroscopic profiles for specific reasons including classification of edible oils or prediction of antioxidant activities using absorbance values of certain spectroscopic methods. Rohman et al. (2020b) have conducted a review on the application of FTIR spectra combined with chemometrics for authentication analysis of fats and oils. However, the application of FTIR spectroscopy combined with chemometrics for the prediction of antioxidant activities is very limited. Casoni et al. (2019) have successfully classified edible vegetable oils based on their UV-Vis spectra and the profiles of DPPH radical scavenging combined with chemometrics of pattern recognition of principal component analysis (PCA) and fuzzy-PCA. The combination of proton $(1 \mathrm{H})-$ NMR and proton (31P)-NMR spectroscopy and chemometrics of discriminant analysis were successful for the classification of 13 types of edible vegetable oils (Vigli et al., 2003). The other spectroscopic techniques combined with chemometrics applied in the classification of oils in different states are FTIR spectroscopy (Lu and Rasco, 2012; Valasi et al., 2020) and fluorescence spectroscopy (Cao et al., 2017). However, using literature investigation, there is no reported publication on the application of FTIR spectra for the classification of PSO. Therefore, the objectives of this study were (1) to classify PSO from different origins based on FTIR spectra and chemometrics of PCA and cluster analysis (CA) and (2) to predict DPPH radical scavenging activities based on FTIR spectra combined with the multivariate calibration of partial least square.

\section{MATERIALS AND METHODS}

\section{Materials}

Pumpkin seeds were obtained from several locations around Yogyakarta and Central Java, Indonesia. The pumpkin fruit was authenticated in the Laboratory of Pharmacognosy, Department of Pharmaceutical Biology, Faculty of Pharmacy,
Universitas Gadjah Mada, under the supervision of Dr. Djoko Santosa. DPPH was purchased from Sigma (Aldrich, St. Louis, $\mathrm{MO})$. The other reagents and solvents used for analysis were of analytical grade obtained from E. Merck (Darmstadt, Germany).

\section{Microwave pretreatment}

Microwave pretreatment of pumpkin seeds was carried out according to the method described by Azadmard-Damirchi et al. (2010). Pumpkin seed samples (100 g) were placed in an even layer in Pyrex Petri dishes inside the microwave (Hitachi, model MR-5750). Samples were microwave treated at a power of $50 \%$ for 240 seconds.

\section{Oil extraction by pressing}

PSO was extracted from the microwave-treated pumpkin seed samples by mechanical hot pressing (Maksindo MKS-J03) according to the method described by Dang and Bui (2019). The oil was later separated from the sediment by centrifugation at 2,500 rpm (Thermo Scientific) for 10 minutes and stored in a freezer at $-20^{\circ} \mathrm{C}$ for subsequent analysis.

\section{DPPH radical scavenging activity (RSA) assay}

DPPH radical scavenging assay was carried out according to Casoni et al. (2019). PSO samples were diluted with ethanol in a $10 \mathrm{ml}$ volumetric flask. For each of the analyzed PSO samples, total radical scavenging capacity was determined by measuring the absorbance of DPPH solution $0.4 \mathrm{mM}$ at $515 \mathrm{~nm}$ (Abs control) and the absorbance of DPPH solution added with the evaluated PSO samples after a reaction time of 30 minutes (Abs sample). All absorbance measurements were corrected with the absorbance of blank containing solvent and the studied PSO samples. For the calculation of RSA percentage (\%), the following formula was used:

Percentage $(\%)$ of DPPH radical scavenging activity $=$

$$
\frac{(\text { Abs control-Abs sample })}{\text { Abs control }} \times 100 \% \text {. }
$$

\section{FTIR spectra measurement}

The FTIR spectra of studied PSO samples were carried out using the conditions as previously reported by Irnawati et al. (2020). The spectra were scanned using an FTIR spectrophotometer (Thermo Scientific Nicolet iS10, Madison, WI), controlled with the operating Omnic software. The measurements were carried out in a mid-infrared region of 4,000-650 $\mathrm{cm}^{-1}$ with a scanning number of 32 and a resolution of $8 \mathrm{~cm}^{-1}$. The used sampling accessory was horizontal attenuated total reflectance composed of ZnSe crystal. All FTIR spectra were corrected against the FTIR spectrum of air as background. After every scan, a new reference air background spectrum was taken. These spectra recorded as absorbance values at each data point in triplicate were used for making the correlation between antiradical activity and FTIR spectra.

\section{Chemometrics analysis}

The absorbance values of FTIR spectra were used as variables during the classification of PSO samples from different regions with the aid of chemometrics of PCA and CA. Furthermore, the prediction of DPPH RSA using a variable of absorbance values 
of FTIR spectra was assisted with the multivariate calibration of partial least square. All chemometric analyses [PCA, CA, and partial least square (PLS)] were carried out using Minitab ${ }^{\circledR}$ version 17 (Minitab Inc., State College, PA).

\section{RESULTS AND DISCUSSION}

In this study, the antioxidant activities of PSO from different regions around Yogyakarta and Central Java, Indonesia, were evaluated by DPPH radical scavenging activities. This technique was based on the capability of chemical compounds present in PSO to reduce DPPH radicals into nonradicals (Rohman et al., 2006; Widyastuti et al., 2021). Table 1 shows the percentage

Table 1. Radical scavenging activities of pumpkin seed oils (PSOs) from different origins at concentration levels of $100 \mu 1 / 5 \mathrm{ml}$.

\begin{tabular}{cc}
\hline Origins & Radical scavenging activity (\%) \\
\hline Blora & $44.20 \pm 0.07$ \\
Boyolali & $40.88 \pm 0.26$ \\
Ceppu & $50.67 \pm 0.75$ \\
Godean & $42.82 \pm 0.22$ \\
Gunung Kidul & $98.71 \pm 0.02$ \\
Gondomanan & $48.04 \pm 0.82$ \\
Grabag & $73.70 \pm 0.27$ \\
Kopeng & $58.95 \pm 0.07$ \\
Kudus & $53.04 \pm 0.22$ \\
Muntilan & $64.77 \pm 0.20$ \\
Palagan & $61.23 \pm 0.33$ \\
Parakan & $54.51 \pm 0.27$ \\
Pati & $60.67 \pm 0.00$ \\
Purwodadi & $49.20 \pm 0.86$ \\
Tawangmangu & $83.57 \pm 0.13$ \\
Weleri & $67.62 \pm 0.20$ \\
\hline
\end{tabular}

of DPPH radical scavenging activities of PSO with a concentration of PSOs of $20 \mu \mathrm{l} / \mathrm{ml}$. The RSA of PSOs from Gunung Kidul and Tawangmangu had the highest RSA among others, accounting for $98.71 \% \pm 0.02 \%$ and $83.57 \% \pm 0.13 \%$, respectively.

In order to classify PSOs from different origins, two chemometric classifications, namely, PCA and CA, were used. PCA and CA are unsupervised pattern recognition in chemometrics analysis (Che Man et al., 2011). PCA is a feature for the reduction of the amount of data when there is a correlation present (Miller and Miller, 2010). In this study, PCA was accomplished using FTIR-ATR spectra absorbance of 16 PSO samples at 14 wavenumber and radical scavenging activities, as shown in Table 2. Each peak or shoulder is associated with structural or functional group information in PSO (Saucedo-Hernández et al., 2011). The functional group and vibration mode for the absorption of peak and shoulder in PSO are presented in Table 3. The functional groups represented in FTIR spectra are correlating with chemical compounds present in PSO. Edible fats and oils including PSO are mainly composed of triacylglycerols (TAG) in approximately $95 \%-98 \%$; as a consequence, the functional groups present in TAG dominate (Rohman et al., 2020c). The functional groups of methyl, methylene, ether, carbonyl, and backbone of fatty acids are represented in FTIR spectra. In addition, the functional groups which are representative for the minor components like functional group of $-\mathrm{OH}$ phenolics disappear due to the low levels; therefore, they are not detected in FTIR spectra. Figure 1 shows the score plot of PCA of 16 PSOs from different origins representing the projection of samples defined by the first principal component (PC1) and the second principal component (PC2). An eigenvalue of about $99.3 \%$ was achieved using six PCs (Fig. 2). The variance $(69.7 \%)$ is being described by PC1 and PC2. PC1 accounted for $49.2 \%$ of the variation, while PC2 described $20.4 \%$ of the variation. Figure 3 shows the loading plot for the determination of wavenumbers contributing to the separation of the PSO from different origins. Based on the loading plot, the wavenumbers at

Table 2. Peak absorbances for each wavenumbers and radical scavenging activity of PSO from different origins.

\begin{tabular}{|c|c|c|c|c|c|c|c|c|c|c|c|c|c|c|c|}
\hline \multirow{2}{*}{ No. } & \multirow{2}{*}{ Origins } & \multicolumn{14}{|c|}{ Absorbance values at different wavenumbers $\left(\mathrm{cm}^{-1}\right)$} \\
\hline & & 721 & 850 & 996 & 1,118 & 1,160 & 1,237 & 1,376 & 1,460 & 1,654 & 1,744 & 2,853 & 2,922 & 2,953 & 3,007 \\
\hline 1 & Blora & 0.0993 & 0.0335 & 0.0405 & 0.0999 & 0.1651 & 0.0762 & 0.0471 & 0.0800 & 0.0104 & 0.2540 & 0.1659 & 0.2387 & 0.0783 & 0.0246 \\
\hline 2 & Boyolali & 0.0975 & 0.0293 & 0.0386 & 0.0978 & 0.1622 & 0.0739 & 0.0459 & 0.0783 & 0.0135 & 0.2493 & 0.1609 & 0.2319 & 0.0770 & 0.0249 \\
\hline 3 & Gondomanan & 0.1001 & 0.0334 & 0.0407 & 0.0985 & 0.1646 & 0.0759 & 0.0469 & 0.0788 & 0.0100 & 0.2541 & 0.1623 & 0.2339 & 0.0784 & 0.0256 \\
\hline 4 & Ceppu & 0.0975 & 0.0334 & 0.0407 & 0.0988 & 0.1625 & 0.0759 & 0.0465 & 0.0789 & 0.0100 & 0.2504 & 0.1625 & 0.2343 & 0.0775 & 0.0246 \\
\hline 5 & Godean & 0.0987 & 0.0349 & 0.0491 & 0.1150 & 0.1641 & 0.0740 & 0.0456 & 0.0759 & 0.0117 & 0.2420 & 0.1538 & 0.2225 & 0.0764 & 0.0261 \\
\hline 6 & Gunung Kidul & 0.0969 & 0.0312 & 0.0402 & 0.0974 & 0.1589 & 0.0721 & 0.0443 & 0.0753 & 0.0083 & 0.2429 & 0.1523 & 0.2183 & 0.0734 & 0.0241 \\
\hline 7 & Kopeng & 0.0979 & 0.0335 & 0.0413 & 0.0994 & 0.1623 & 0.0750 & 0.0464 & 0.0786 & 0.0093 & 0.2470 & 0.1608 & 0.2307 & 0.0766 & 0.0245 \\
\hline 8 & Muntilan & 0.0984 & 0.0333 & 0.0408 & 0.0982 & 0.1636 & 0.0753 & 0.0466 & 0.0793 & 0.0089 & 0.2517 & 0.1649 & 0.2372 & 0.0776 & 0.0244 \\
\hline 9 & Palagan & 0.1030 & 0.0350 & 0.0432 & 0.0976 & 0.1660 & 0.0766 & 0.0474 & 0.0788 & 0.0098 & 0.2550 & 0.1590 & 0.2290 & 0.0783 & 0.0268 \\
\hline 10 & Parakan & 0.1008 & 0.0342 & 0.0414 & 0.0930 & 0.1550 & 0.0716 & 0.0439 & 0.0726 & 0.0093 & 0.2315 & 0.1372 & 0.1946 & 0.0674 & 0.0250 \\
\hline 11 & Pati & 0.0975 & 0.0334 & 0.0417 & 0.0994 & 0.1626 & 0.0747 & 0.0457 & 0.0777 & 0.0088 & 0.2488 & 0.1602 & 0.2305 & 0.0763 & 0.0237 \\
\hline 12 & Weleri & 0.1020 & 0.0347 & 0.0424 & 0.0956 & 0.1620 & 0.0742 & 0.0460 & 0.0764 & 0.0094 & 0.2450 & 0.1510 & 0.2150 & 0.0723 & 0.0247 \\
\hline 13 & Kudus & 0.1010 & 0.0347 & 0.0427 & 0.0987 & 0.1650 & 0.0761 & 0.0473 & 0.0796 & 0.0100 & 0.2540 & 0.1620 & 0.2330 & 0.0778 & 0.0251 \\
\hline 14 & Grabag & 0.1030 & 0.0349 & 0.0426 & 0.0965 & 0.1650 & 0.0756 & 0.0469 & 0.0777 & 0.0098 & 0.2510 & 0.1550 & 0.2230 & 0.0760 & 0.0266 \\
\hline 15 & Purwodadi & 0.1000 & 0.0348 & 0.0429 & 0.0986 & 0.1640 & 0.0756 & 0.0470 & 0.0791 & 0.0096 & 0.2510 & 0.1620 & 0.2310 & 0.0762 & 0.0242 \\
\hline 16 & Tawangmangu & 0.1031 & 0.0336 & 0.0412 & 0.0944 & 0.1615 & 0.0748 & 0.0459 & 0.0748 & 0.0095 & 0.2439 & 0.1451 & 0.2088 & 0.0734 & 0.0268 \\
\hline
\end{tabular}


Table 3. Functional groups responsible for absorption of peaks and shoulders in PSO.

\begin{tabular}{cll}
\hline Wavenumber region $\left(\mathbf{c m}^{-1}\right)$ & Functional groups & Vibration modes \\
\hline 3,007 & cis- $\mathrm{C}=\mathrm{CH}$ & Stretching vibration \\
2,953 & Methylene $(-\mathrm{CH} 2)$ & Asymmetric stretching vibration \\
2,922 and 2,852 & Methylene $(-\mathrm{CH} 2)$ & Asymmetric and symmetric Stretching vibrations \\
1,744 & Carbonyl $(\mathrm{C}=\mathrm{O})$ & Stretching vibration \\
1,654 & $\mathrm{C}=\mathrm{C}$ & Stretching vibration \\
1,460 & Methylene $(-\mathrm{CH} 2)$ & Bending vibration (scissoring $)$ \\
1,376 & Methyl $(-\mathrm{CH} 3)$ & Symmetric bending vibration \\
$1,234,1,160$ & Methylene $(-\mathrm{CH} 2)$ & Bending vibration \\
$1,118,1,097$ & $\mathrm{C}-\mathrm{O}$ & Stretching vibrations \\
996 & $-\mathrm{HC}=\mathrm{CH}-($ trans $)$ & Bending out of plane \\
850 & $=\mathrm{CH} 2$ & Wagging \\
721 & $-(\mathrm{CH} 2)_{\mathrm{n}}$ & Rocking \\
\hline
\end{tabular}

Adapted from Saucedo-Herna et al. (2011).

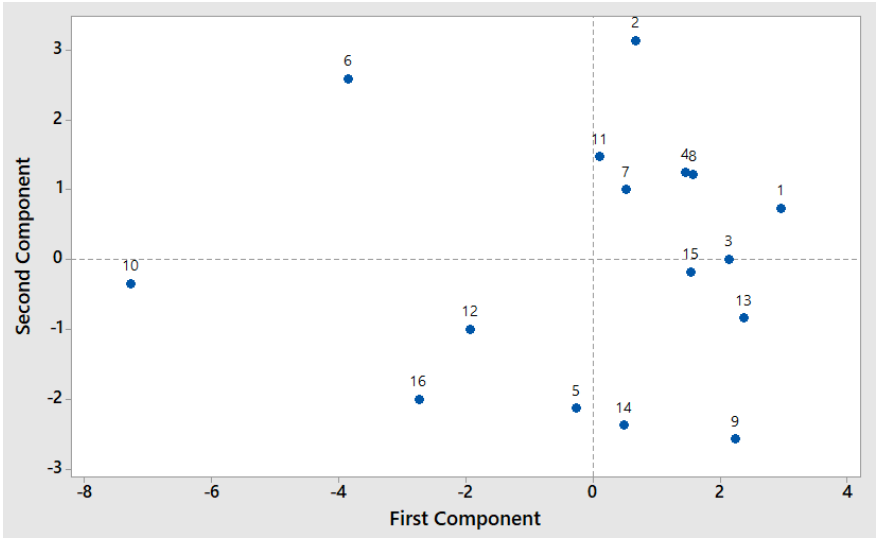

Figure 1. The PCA score plot of pumpkin seed oils (PSOs) from different origins: (1) Blora; (2) Boyolali; (3) Gondomanan; (4) Ceppu; (5) Godean; (6) Gunung Kidul; (7) Kopeng; (8) Muntilan; (9) Palagan; (10) Parakan; (11) Pati; (12) Weleri; (13) Kudus; (14) Grabag; (15) Purwodadi; (16) Tawangmangu.

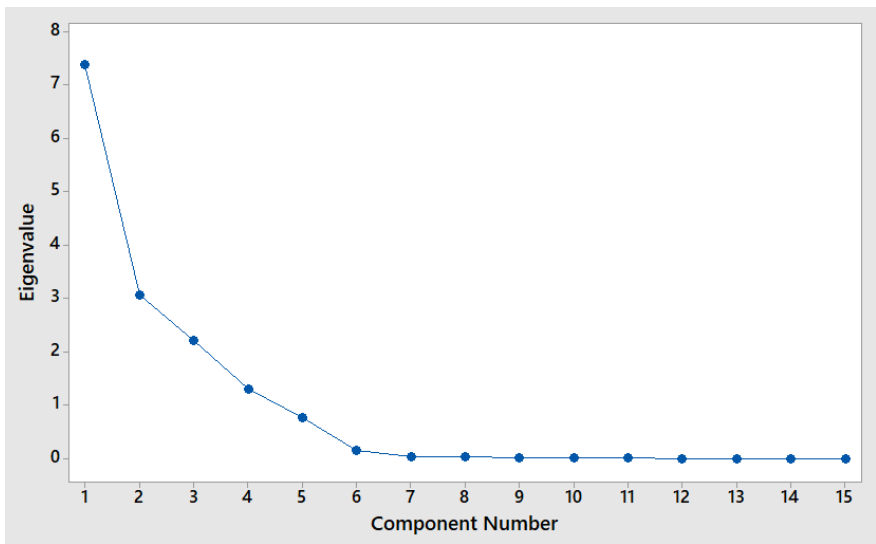

Figure 2. Eigenvalue of PCA of PSO from different origins.

$2,953,1,460$, and $1,160 \mathrm{~cm}^{-1}$ made a large contribution to the PCA model.

CA is a hierarchical method in which successive partition of the data set results in a cluster represented as a

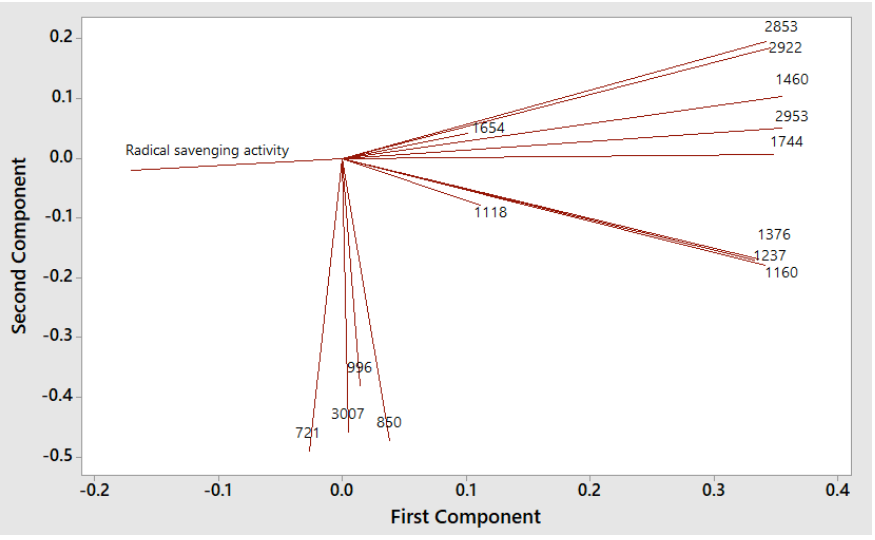

Figure 3. The loading plot of PCA models of PSO from different origins.

dendrogram or tree (Djuris et al., 2013). In addition, CA can provide numerical values of similarity among the objects evaluated and therefore obtained more objective information (Che Man et al., 2011). We divided a group of PSOs from different origins into classes so that similar characteristics of PSO are in the same class. The classification stages of PSO can be seen in Table 4. It can be stated that the first joined are PSOs from Palagan and Pati, followed by PSOs from Gondomanan and Purwodadi with distance levels being 0.5607 and 0.1643 , respectively, and so on until all PSOs from different origins are grouped into one class. Figure 4 showed a dendrogram using the single linkage method. This analysis suggests that the evaluated PSOs from different origins fall into five groups. Group 1 contained PSO from Palagan, Pati, Kopeng, Muntilan, and Weleri; PSOs from Gondomanan, Purwodadi, Ceppu, Parakan, and Kudus formed group 2; PSOs from Blora, Godean, and Boyolali formed group 3; PSOs from Grabag and Tawangmangu formed group 4. Meanwhile, PSO from Gunung Kidul formed a separate group (group 5).

The multivariate calibration of PLSR was used for the prediction of antioxidant activities through DPPH radical scavenging activities using absorbance values of FTIR spectra as variables during modeling. The variation in FTIR spectra of 
Table 4. The classification stages of PSO from different origins.

\begin{tabular}{cccccccc}
\hline Step & $\begin{array}{c}\text { Number of } \\
\text { clusters }\end{array}$ & $\begin{array}{c}\text { Similarity } \\
\text { level }\end{array}$ & Distance level & Clusters joined & New cluster & $\begin{array}{c}\text { Number of obs. } \\
\text { in new cluster }\end{array}$ \\
\hline 1 & 15 & 99.0304 & 0.5607 & 9 & 11 & 9 & 2 \\
2 & 14 & 97.9866 & 1.1643 & 3 & 15 & 3 & 2 \\
3 & 13 & 97.6132 & 1.3802 & 1 & 5 & 1 & 2 \\
4 & 12 & 97.4629 & 1.4671 & 10 & 13 & 10 & 2 \\
5 & 11 & 96.0477 & 2.2855 & 7 & 9 & 7 & 3 \\
6 & 10 & 95.4511 & 2.6304 & 3 & 4 & 3 & 3 \\
7 & 9 & 95.0781 & 2.8462 & 8 & 12 & 8 & 2 \\
8 & 8 & 94.2580 & 3.3204 & 1 & 2 & 1 & 3 \\
9 & 7 & 89.7091 & 5.9509 & 14 & 16 & 14 & 2 \\
10 & 6 & 88.8139 & 6.4685 & 3 & 10 & 3 & 5 \\
11 & 5 & 85.0111 & 8.6676 & 7 & 8 & 7 & 5 \\
12 & 4 & 76.4353 & 13.6267 & 1 & 3 & 1 & 8 \\
13 & 3 & 64.2058 & 20.6986 & 7 & 14 & 7 & 7 \\
14 & 2 & 32.9605 & 38.7667 & 1 & 7 & 1 & 15 \\
15 & 1 & 0.0000 & 57.8267 & 1 & 6 & 1 & 16 \\
\hline
\end{tabular}

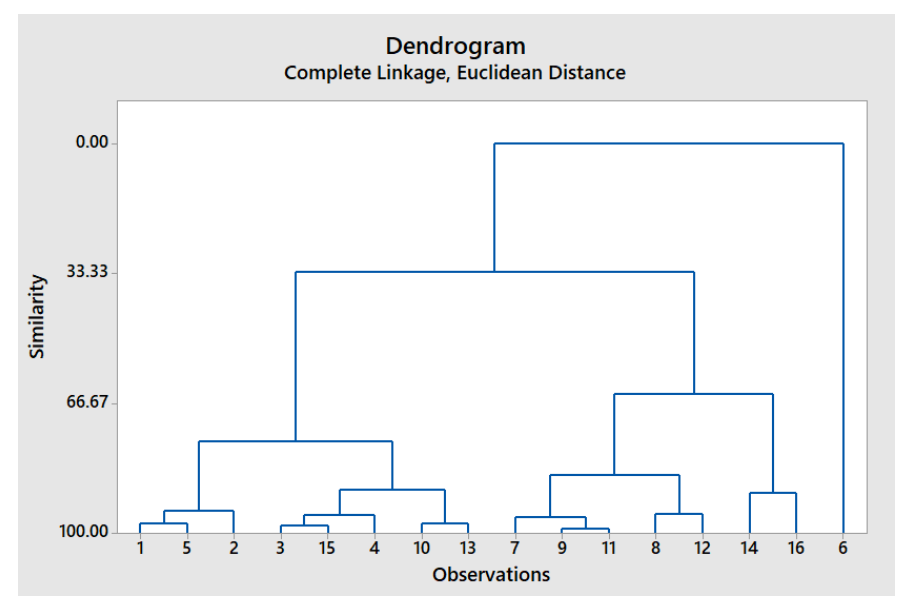

Figure 4. The dendrogram of PSOs from different origins: (1) Blora; (2) Boyolali; (3) Gondomanan; (4) Ceppu; (5) Godean; (6) Gunung Kidul; (7) Kopeng; (8) Muntilan; (9) Palagan; (10) Parakan; (11) Pati; (12) Weleri; (13) Kudus; (14) Grabag; (15) Purwodadi; (16) Tawangmangu.

PSO was used to build a calibration model for the prediction of radical scavenging activities in PSO. In this study, to obtain the best prediction model, the wavenumber regions $(3,900-650$, $3,500-650,1,700-650,1,130-700$, and combined wavenumbers of 3,050-2,800 and $\left.1,790-650 \mathrm{~cm}^{-1}\right)$ and FTIR spectral treatment (normal, first derivative, and second derivative) were optimized. Spectra derivatization is able to produce better resolution (Windarsih et al., 2020). Table 5 shows the optimization of the calibration model using the PLS calibration model. The selection of optimum conditions was based on the highest coefficient correlation and the lowest root mean square error of calibration (RMSEC) and the root mean square error of prediction (RMSEP) (Irnawati et al., 2019). Finally, the first derivative FTIR spectra at wavenumber region at $3,500-650 \mathrm{~cm}^{-1}$ were selected for the prediction of RSA in PSO with $R^{2}$ value of 0.9996 and 0.9418 in calibration and validation models, while RMSEC and RMSEP were $0.425 \%$ and $4.93 \%$, respectively (Fig. $5 a$ ). Figure
Table 5. Multivariate calibration of PLSmodel for the prediction of radical scavenging activity in PSO.

\begin{tabular}{|c|c|c|c|c|c|c|}
\hline \multirow{2}{*}{$\begin{array}{l}\text { Multivariate } \\
\text { calibrations }\end{array}$} & \multirow{2}{*}{$\begin{array}{l}\text { Wavenumber } \\
\left(\mathrm{cm}^{-1}\right)\end{array}$} & \multirow{2}{*}{ Spectra } & \multicolumn{2}{|c|}{ Calibration } & \multicolumn{2}{|c|}{ Validation } \\
\hline & & & $R^{2}$ & RMSEC & $R^{2}$ & RMSEP \\
\hline \multirow[t]{15}{*}{ PLS } & \multirow{3}{*}{$3,900-650$} & normal & 0.6316 & 11.700 & 0.6455 & 11.000 \\
\hline & & 1 st der & 0.9994 & 0.536 & 0.9403 & 4.900 \\
\hline & & 2nd der & 0.9956 & 1.410 & 0.8985 & 6.260 \\
\hline & \multirow{3}{*}{$3,500-650$} & normal & 0.6286 & 11.800 & 0.6429 & 11.100 \\
\hline & & 1 st der & 0.9996 & 0.425 & 0.9418 & 4.930 \\
\hline & & 2nd der & 0.9945 & 1.590 & 0.9165 & 5.690 \\
\hline & \multirow{3}{*}{$1,700-650$} & normal & 0.5060 & 13.000 & 0.5643 & 11.700 \\
\hline & & 1 st der & 0.9813 & 2.910 & 0.9173 & 5.730 \\
\hline & & 2nd der & 0.5382 & 12.700 & 0.4284 & 13.000 \\
\hline & \multirow{3}{*}{$1,130-700$} & normal & 0.3558 & 14.100 & 0.4240 & 12.900 \\
\hline & & 1 st der & 0.6700 & 11.200 & 0.6287 & 11.100 \\
\hline & & 2nd der & 0.5179 & 12.900 & 0.4028 & 13.200 \\
\hline & \multirow{3}{*}{$\begin{array}{c}3,050-2,800 \\
\text { and } \\
1,790-650\end{array}$} & normal & 0.6316 & 11.700 & 0.6455 & 11.000 \\
\hline & & 1 st der & 0.9994 & 0.536 & 0.9403 & 4.900 \\
\hline & & 2nd der & 0.9956 & 1.410 & 0.8985 & 6.260 \\
\hline
\end{tabular}

$5 \mathrm{~b}$ shows the residual analysis between actual and predicted value. It is clear that all point differences are located above and below zero value; therefore, the systematic error during PLS modeling between actual values of antioxidant activities and FTIR predicted values could be negligible. The capability of FTIR spectroscopy combined with chemometrics to predict the antioxidant activities is not surprising because FTIR spectra are fingerprints in nature so that the analyst can select the peaks in FTIR spectra which correlated with the antioxidant activities to be predicted with antioxidant activities. Because of its benefits, in the future, it is hoped that FTIR spectra combined with chemometrics techniques of multivariate calibration can be used as an alternative method for determining the antioxidant activity of PSO in vitro. 
(a)

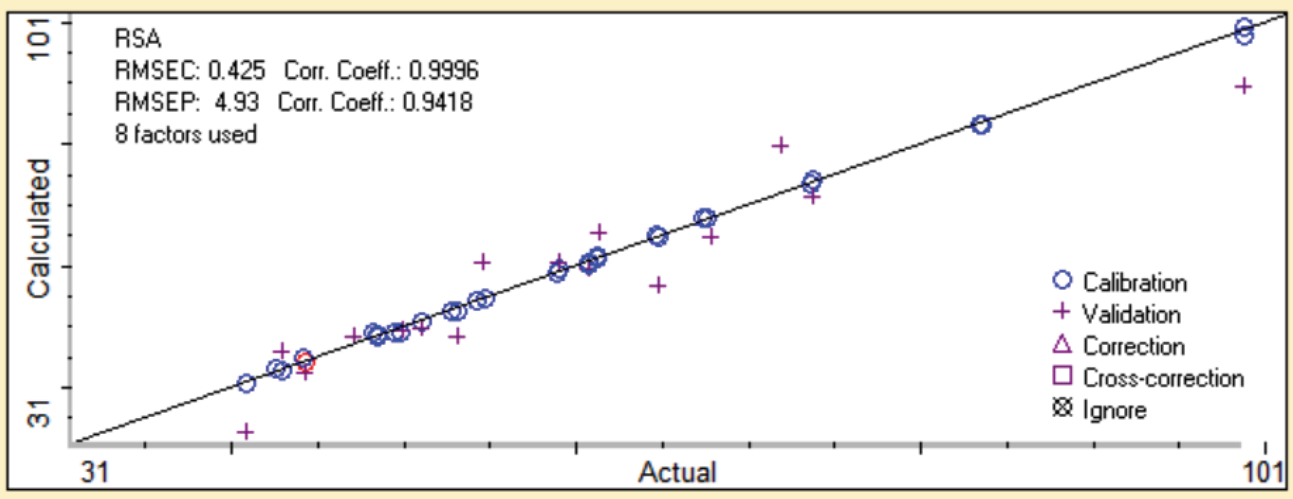

(b)

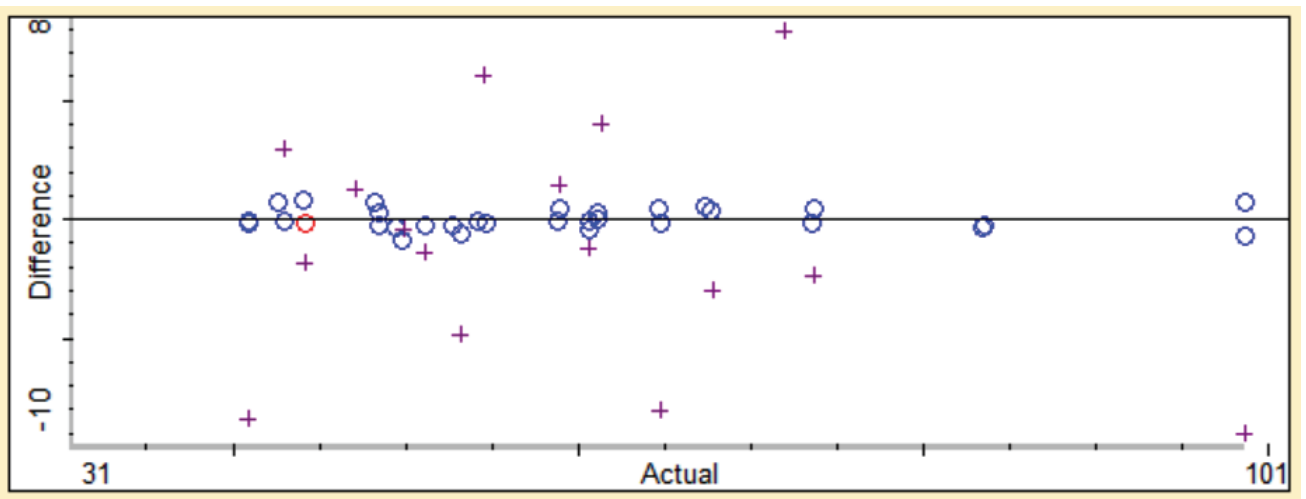

Figure 5. PLS calibration model (a) and residual factor (b) for prediction of radical scavenging activity in PSO. The $x$-axis showed the actual radical scavenging activity in PSO; the $y$-axis showed the calculated radical scavenging activity of PSO.

\section{CONCLUSION}

FTIR spectra combined with chemometrics techniques are effective means for the classification of PSO from different origins and for the prediction of antioxidant activities. PCA and CA were successfully applied for the classification of PSOs from different origins as indicated by clear separation among the evaluated samples. In addition, PLS regression was also accurate and precise for predicting the antioxidant activities as indicated by a high coefficient of determination $\left(R^{2}\right)$ and low errors. The developed method is considered a green analytical technique due to the use of less solvent and with minimum sample preparation; therefore, the method could be considered an alternative method for determining antioxidant activities.

\section{ACKNOWLEDGEMENTS}

The authors acknowledge the Ministry of Research, Technology and Higher Education, Republic of Indonesia, for financial support during this study through Hibah Penelitian Dasar Unggulan Perguruan Tinggi (PUPT) 2020 with contract number 1761/UN1.DITLIT/DIT-LIT/LT/2020.

\section{AUTHOR CONTRIBUTIONS}

All authors made substantial contributions to conception and design, acquisition of data, or analysis and interpretation of data; took part in drafting the article or revising it critically for important intellectual content; agreed to submit to the current journal; gave final approval of the version to be published; and agree to be accountable for all aspects of the work. All the authors are eligible to be an author as per the international committee of medical journal editors (ICMJE) requirements/guidelines.

\section{CONFLICTS OF INTEREST}

The authors report no financial or any other conflicts of interest in this work.

\section{ETHICAL APPROVALS}

This study does not involve experiments on animals or human subjects.

\section{PUBLISHER'S NOTE}

This journal remains neutral with regard to jurisdictional claims in published institutional affiliation.

\section{REFERENCES}

Alam MN, Bristi NJ, Rafiquzzaman M. Review on in vivo and in vitro methods evaluation of antioxidant activity. Saudi Pharm J, 2013; 21(2):143-52.

Al-Farsi M, Alasalvar C, Morris A, Baron M, Shahidi F. Comparison of antioxidant activity, anthocyanins, carotenoids, and 
phenolics of three native fresh and sun-dried date (Phoenix dactylifera L.) varieties grown in Oman. J Agric Food Chem, 2005; 53(19):7592-9.

Azadmard-Damirchi S, Habibi-Nodeh F, Hesari J, Nemati M, Achachlouei BF. Effect of pretreatment with microwaves on oxidative stability and nutraceuticals content of oil from rapeseed. Food Chem, 2010; 121(4):1211-5.

Cao J, Li C, Liu R, Liu XR, Fan Y, Deng ZY. Combined application of fluorescence spectroscopy and chemometrics analysis in oxidative deterioration of edible oils. Food Anal Methods, 2017; 10(3):649 58.

Casoni D, Simion IM, Sârbu C. A comprehensive classification of edible oils according to their radical scavenging spectral profile evaluated by advanced chemometrics. Spectrochim Acta A Mol Biomol Spectrosc, 2019; 213:204-9.

Che Man YB, Rohman A, Mansor TST. Differentiation of lard from other edible fats and oils by means of Fourier transform infrared spectroscopy and chemometrics. J Am Oil Chem Soc, 2011; 88(2):187-92.

Dang TQ, Bui HQH. Effect of roasting and microwave heating on the yield, quality, total phenolics and antioxidant capacity of oil from red pumpkin seed. EC Nutr, 2019; 8:588-96.

Djuris J, Ibric S, Djuric Z. Chemometric methods application in pharmaceutical products and processes analysis and control. In: Djuris J (ed.). Computer-aided applications in pharmaceutical technology. Woodhead Publishing Limited, Cambridge, UK, pp 57-90, 2013.

Irnawati, Riyanto S, Martono S, Rohman A. Analysis of palm oil as oil adulterant in olive and pumpkin seed oils in ternary mixture systems using ftir spectroscopy and chemometrics. Int J Appl Pharm, 2019; 11(5):210-5.

Irnawati I, Riyanto S, Martono S, Rohman A. The employment of FTIR spectroscopy and chemometrics for authentication of pumpkin seed oil sesame oil. Food Res, 2020; 4(1):42-8.

Jiao J, Li ZG, Gai QY, Li XJ, Wei FY, Fu YJ, Ma W. Microwaveassisted aqueous enzymatic extraction of oil from pumpkin seeds and evaluation of its physicochemical properties, fatty acid compositions and antioxidant activities. Food Chem, 2014; 147:17-24

Kulaitienė J, Černiauskienė J, Jarienė E, Danilčenko $H$, Levickienè D. Antioxidant activity and other quality parameters of cold pressing pumpkin seed oil. Not Bot Hortic Agrobo, 2018; 46(1):161-6.

$\mathrm{Lu} \mathrm{X}$, Rasco BA. Determination of antioxidant content and antioxidant activity in foods using infrared spectroscopy and chemometrics: a review. Crit Rev Food Sci Nutr, 2012; 52(10):853-75.

Marina AM, Che Man YB, Nazimah SAH, Amin I. Chemical properties of virgin coconut oil. J Am Oil Chem Soc, 2009; 86(4):301-7.

Miller JN, Miller JC. Statistics and chemometrics for analytical chemistry. 6th edition, Prentice Hall, Harlow, UK, p 278, 2010.

Rezig L, Chouaibi M, Ojeda-Amador RM, Gomez-Alonso S, Salvador MD, Fregapane G, Hamdi S. Cucurbita maxima pumpkin seed oil: From the chemical properties to the different extracting techniques. Not Bot Hortic Agrobotanici Cluj-Napoca, 2018; 46(2):663-9.

Rohman A, Ghazali MAB, Windarsih A, Irnawati, Riyanto S, Yusof FM, Mustafa S. Comprehensive review on application of FTIR spectroscopy coupled with chemometrics for authentication analysis of fats and oils in the food products. Molecules, 2020b; 25:1-28.
Rohman A, Irnawati. Pumpkin (Cucurbita maxima) seed oil: chemical composition, antioxidant activities and its authentication analysis. Food Res, 2020c; 4(3):578-84.

Rohman A, Riyanto S, Utari U. Antioxidant activity and total phenolic content of ethyl acetate extract of Mengkudu (Morinda citrifolia L.) fruit. Indones J Pharm, 2006; 17(2):136-42.

Rohman A, Widodo H, Lukitaningsih E, Windarsih A, Rafi M, Nurrulhidayah AF. Review on in vitro antioxidant activities of curcuma species commonly used as herbal components in Indonesia. Food Res, 2020a; 4(2):286-93.

Saucedo-Hernández Y, Lerma-García MJ, Herrero-Martínez JM, Ramis-Ramos G, Jorge-Rodríguez E, Simó-Alfonso EF. Classification of pumpkin seed oils according to their species and genetic variety by attenuated total reflection fourier-transform infrared spectroscopy. J Agric Food Chem, 2011; 59(8):4125-9.

Siano F, Straccia MC, Paolucci M, Fasulo G, Boscaino F, Volpe MG. Physico-chemical properties and fatty acid composition of pomegranate, cherry and pumpkin seed oils. J Sci Food Agric, 2016; 96:1730-5

Valasi L, Arvanitaki D, Mitropoulou A, Georgiadou M, Pappas CS. Study of the quality parameters and the antioxidant capacity for the Ftir-chemometric differentiation of pistacia vera oils. Molecules, 2020; 25(7): 1614

Vigli G, Philippidis A, Spyros A, Dais P. Classification of edible oils by employing $31 \mathrm{P}$ and $1 \mathrm{H}$ NMR spectroscopy in combination with multivariate statistical analysis. A proposal for the detection of seed oil adulteration in virgin olive oils. J Agric Food Chem, 2003; 51(19):5715-22.

Widodo H, Sismindari S, Asmara W, Rohman A. Antioxidant activity, total phenolic and flavonoid contents of selected medicinal plants used for liver diseases and its classification with chemometrics. J Appl Pharm Sci, 2019; 9(6):99-105.

Widyastuti I, Luthfah HZ, Hartono YI, Islamadina R, Can AT, Rohman A. Antioxidant Activity of Temulawak (Curcuma xanthorrhiza Roxb.) and its classification with chemometrics. Indones J Chemom Pharm Anal, 2021; 1(1):29-42.

Windarsih A, Irnawati, Rohman A. Application of FTIR-ATR spectroscopy and chemometrics for the detection and quantification of lard oil in bovine milk fat. Food Res, 2020; 4(5):1732-8.

Zhang Q, Liu C, Sun Z, Hu X, Shen Q, Wu J. Authentication of edible vegetable oils adulterated with used frying oil by fourier transform infrared spectroscopy. Food Chem, 2012; 132(3):1607-13.

\section{How to cite this article:}

Irnawati I, Riyanto S, Martono S, Rohman A. The employment of FTIR spectroscopy and chemometrics for the classification and prediction of antioxidant activities of pumpkin seed oils from different origins. J Appl Pharm Sci, 2021; 11(05): $100-107$. 


\section{GRAPHICAL ABSTRACT}
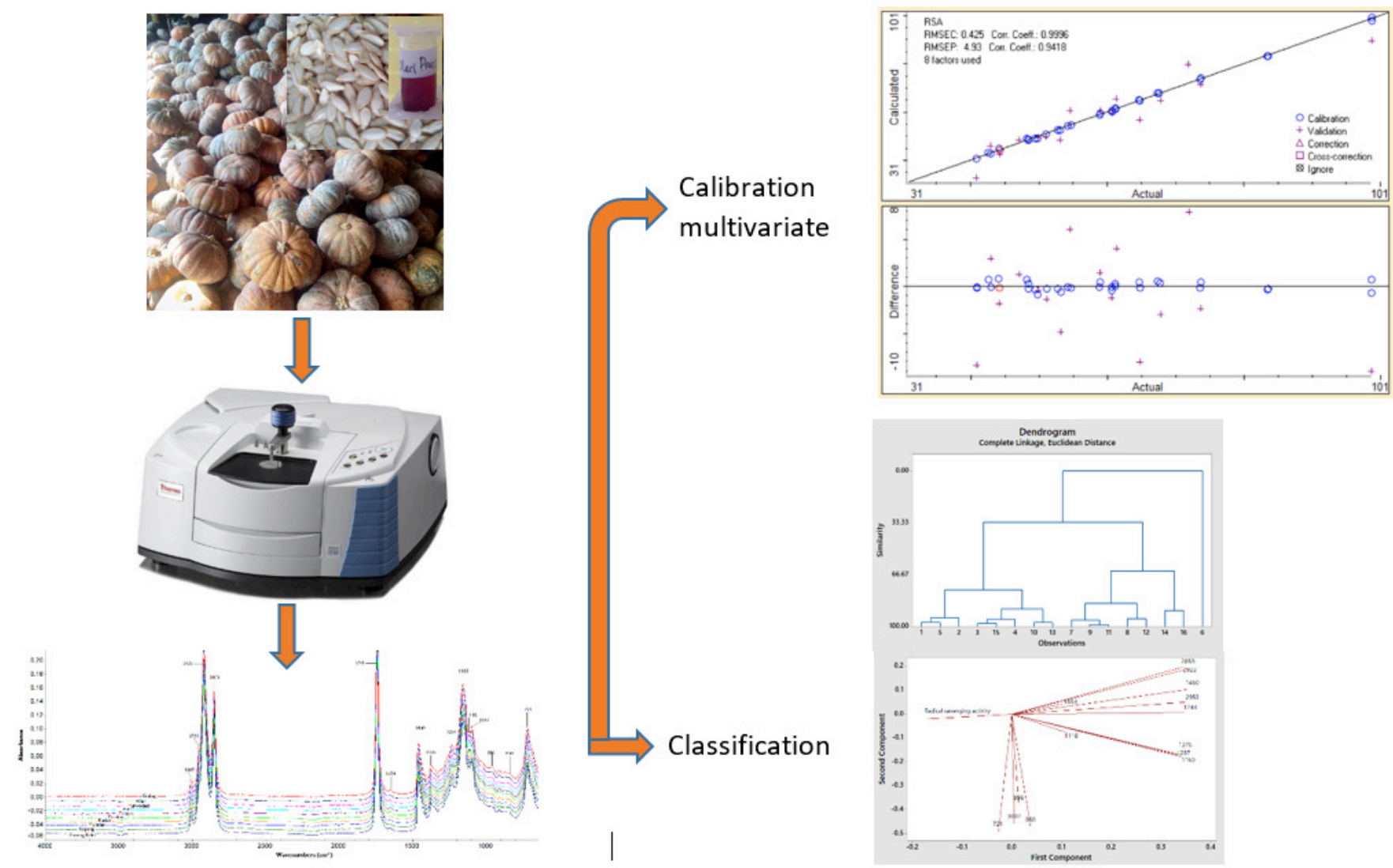

\section{SUMMARY}

1. FTIR spectra combined with chemometrics techniques are effective means for the classification of PSO from different origins and for the prediction of antioxidant activities.

2. PCA and CA were successfully applied for the classification of PSOs from different origins.

3. PLSR was also accurate and precise for predicting the antioxidant activities. 